\title{
High Temperature Dielectric Anisotropy of Poly(vinylidene fluoride) Films at Microwave Frequencies
}

\author{
Shigeyoshi OsAKI \\ Faculty of Education, Shimane University, \\ 1060 Nishikawatsu-cho, Matsue, Shimane 690, Japan
}

(Received August 31, 1995)

\begin{abstract}
Microwave dielectric anisotropy at temperatures between $30^{\circ} \mathrm{C}$ and $102^{\circ} \mathrm{C}$ was measured from the determination of the dielectric constant $\varepsilon^{\prime}$ and loss $\varepsilon^{\prime \prime}$ at $4.0 \mathrm{GHz}$ for uniaxially stretched poly(vinylidene fluoride) (PVDF) films. The $\varepsilon^{\prime}$ increased gradually with increasing temperature, whereas $\varepsilon^{\prime \prime}$ was followed by a sharp upswing with an increase in temperature. These temperature changes in $\varepsilon^{\prime}$ and $\varepsilon^{\prime \prime}$ are attributable to the shift of the dielectric $\alpha$-relaxation swallowing the $\beta$-relaxation to high frequency with an increase in temperature. Time dependence studies on $\varepsilon^{\prime \prime}$ at $4.0 \mathrm{GHz}$ and fixed high temperatures for the uniaxially stretched PVDF film showed a significant decrease in $\varepsilon^{\prime \prime}$ with time only above $c a$. $85^{\circ} \mathrm{C}$. This phenomenon may be ascribed to the crystallization of PVDF molecules in the amorphous region or the shift of the $\alpha$-relaxation to high frequency. The dielectric anisotropy for uniaxially stretched PVDF was also identified even at high temperatures. KEY WORDS Dielectric Constant / Dielectric Loss / Microwave Frequency / High Temperature / Poly(vinylidene fluoride) / Anisotropy /
\end{abstract}

Many reports ${ }^{1-4}$ on dielectric properties of polymer films have been presented at audio frequencies in a wide range of temperature while few studies ${ }^{5,6}$ have been yet available at microwave frequencies. In general the study of the dielectric relaxation at microwave frequencies has been restricted to an estimation from the data below $1 \mathrm{MHz} .{ }^{1,3,7}$ We presented the new microwave method for studying the molecular orientation of polymer films and the dielectric properties at microwave frequencies. $^{8-22}$ The temperature range covered by our microwave method, however, has so far been restricted to room temperature.

It is important to obtain the high temperature dielectric behavior of polymer film at microwave frequencies basically and practically. For example, high temperature data of the microwave dielectric constant $\varepsilon^{\prime}$ and loss $\varepsilon^{\prime \prime}$ of polymer film are useful for elucidating the dielectric $\alpha$ - or $\beta$-relaxation due to the molecular chains at high temperatures and also for evaluating high temperature characteristics of packaging materials in the microwave oven.

In a previous paper ${ }^{23}$ the author made the high temperature microwave dielectric measurements possible, reported the high temperature dielectric loss of poly(vinylidene fluoride) PVDF film at $4.0 \mathrm{GHz}$ and studied the process of crystallization at high temperatures by the contact free measurements.

The present paper describes an experimental study of the temperature dependence of $\varepsilon^{\prime}$ and $\varepsilon^{\prime \prime}$ at $4.0 \mathrm{GHz}$ for uniaxially stretched PVDF films up to $102^{\circ} \mathrm{C}$ and also the time dependence of $\varepsilon^{\prime \prime}$ at $4.0 \mathrm{GHz}$ in the range from $30^{\circ} \mathrm{C}$ to $102^{\circ} \mathrm{C}$

\section{EXPERIMENTAL}

Samples used were uniaxially stretched PVDF films which were supplied by Kureha Chemical Co. The crystalline modification consists of a mixture of type I ( $80 \%)$ and type II $(20 \%)$ according to infrared spectrum. ${ }^{24-25}$
The glass transition temperature of the uniaxially stretched PVDF was estimated to be $-35^{\circ} \mathrm{C}$ by DSC.

Dielectric measurements were carried out by our "high temperature dielectric analyzer" consisting of the cavity resonator system. ${ }^{22}$ The system was completely surrounded by an oven that consisted of heat-resistive, adiabatic sheet materials covered with stainless steel sheets.

The cavity resonator system was heated by blowing hot air into it, with the temperature variation regulated to within $0.3^{\circ} \mathrm{C}$. Hot air blowing into the system minimized temperature fluctuation in the oven. The temperature was measured by a thermocouple placed near the sample.

The time dependence of $\varepsilon^{\prime}$ and $\varepsilon^{\prime \prime}$ at $4.0 \mathrm{GHz}$ was measured as a function of time for a sample kept standing after $3 \mathrm{~min}$ of insertion into the system kept at a fixed high temperature in order to examine whether the annealing at a fixed high temperature gives a change in crystallization or relaxation time due to the rearrangement of molecules. Different samples prepared at the positions of the same TD direction of the film were used for measurements at different temperatures. The temperature dependence of $\varepsilon^{\prime}$ and $\varepsilon^{\prime \prime}$ was measured after $3 \mathrm{~min}$ of the insertion of sample into the system raised at a fixed temperature and the sample was removed out of the system soon after the measurement at a temperature was completed.

The time needed for a single dielectric measurement was $30 \mathrm{~s}$ at any temperature. The cavity system was operated in a transverse electric wave (TE) of type $\mathrm{TE}_{101},{ }^{11,26}$ with the frequency adjusted continuously between 3.8 and $4.2 \mathrm{GHz}$. The sample size was $100 \times 100$ $\mathrm{mm}$ for uniaxially stretched PVDF, with the film thickness being $70 \mu \mathrm{m}$.

The dielectric loss of the sample at temperature $T$ can be calculated from $^{23}$

$$
\varepsilon^{\prime \prime}(T)=B^{\prime}[c(T) / 2 t(T)]\left[\left\{1 / Q_{2}(T)\right\}-\left\{1 / Q_{1}(T)\right\}\right]
$$


Here, $t$ is the sample thickness, $c$ is a parameter relating to the depth of the waveguide, $B^{\prime}$ is an instrumental constant, and $Q_{1}$ and $Q_{2}$ the $Q$ values with subscripts 1 and 2 indicating before and after insertion of the sample in the cavity system.

\section{RESULTS AND DISCUSSION}

Figures 1 and 2 show the temperature dependences of dielectric constant $\varepsilon^{\prime}$ and loss $\varepsilon^{\prime \prime}$ at $4.0 \mathrm{GHz}$, respectively, for uniaxially stretched PVDF film. We see that the increase in $\varepsilon^{\prime}$ with temperature for the PVDF film is weak, whereas that one in $\varepsilon^{\prime \prime}$ is steep above $50^{\circ} \mathrm{C}$. We also see that the difference in $\varepsilon^{\prime}$ and $\varepsilon^{\prime \prime}$ between the transverse direction TD and stretching direction SD (or machine direction MD) of the film becomes large with temperature.

At room temperature the loss peak of the dielectric

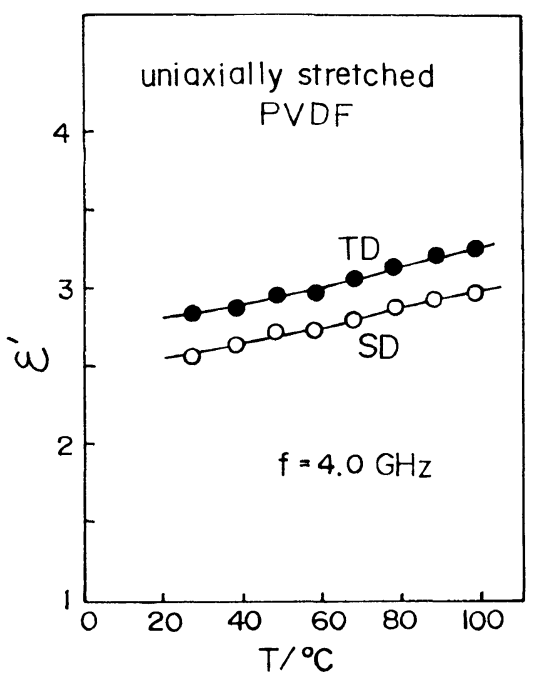

Figure 1. Temperature dependence of $\varepsilon^{\prime}$ at $4.0 \mathrm{GHz}$ for uniaxially stretched PVDF film. The room temperature crystalline forms were determined to be type I $(80 \%)$ and type II $(20 \%)$ according to infrared spectrum. Unfilled circles, data in the SD; filled circles, data in the TD.

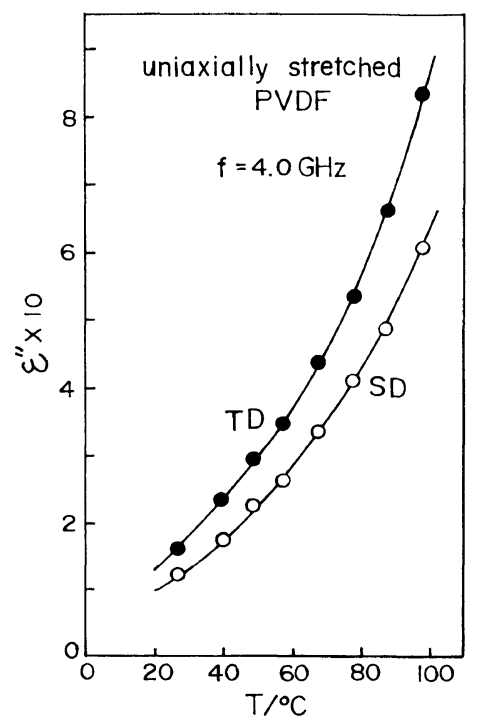

Figure 2. Temperature dependence of $\varepsilon^{\prime \prime}$ at $4.0 \mathrm{GHz}$ for uniaxially stretched PVDF film. The room temperature crystalline forms were determined to be type I $(80 \%)$ and type II $(20 \%)$ according to infrared spectrum. Unfilled circles, data in the SD; filled circles, data in the TD. $\alpha$-relaxation swallowing the $\beta$-relaxation appeared in a frequency region around $10 \mathrm{MHz}$ for unstretched samples. $^{2,3}$ This peak frequency is far lower than $4 \mathrm{GHz}$ at which the present dielectric measurements were made. Hence, $\varepsilon^{\prime \prime}$ at $4.0 \mathrm{GHz}$ for PVDF film at room temperature should be in the high frequency tail of the $\alpha$-relaxation that can arise from the amorphous region, from the magnitute of observed $\varepsilon^{\prime \prime}$ at $4.0 \mathrm{GHz}$ and the relaxation map described in ref (3). As well known, the dielectric loss due to the $\alpha$-relaxation increases with decreasing crystallinity and the increase is most pronounced at the loss peak of this relaxation. The peak shifts toward higher frequency with increasing temperature. Thus, it may be expected that the difference in $\varepsilon^{\prime \prime}$ at $4.0 \mathrm{GHz}$ between two TD and SD directions is ascribed to anisotropy due to molecular orientation ${ }^{19}$ and should become more appreciable at higher temperature. Probably, the loss peak of $\alpha$-relaxation at $4.0 \mathrm{GHz}$ may be observed above $100^{\circ} \mathrm{C}$

Figure 3 shows the time dependence of $\varepsilon^{\prime \prime}$ at $4.0 \mathrm{GHz}$ at $102^{\circ} \mathrm{C}$ in the TD and SD directions for the uniaxially stretched PVDF. Both the $\varepsilon^{\prime \prime}$ decrease with time and then level off. A difference in $\varepsilon^{\prime \prime}$ between the TD and SD was a bit reduced by annealing at the high temperature. Thus, the annealing at temperatures up to $102^{\circ} \mathrm{C}$ gave an appreciable effect on the dielectric anisotropy.

Figure 4 shows the time dependence of $\varepsilon^{\prime \prime}$ at $4.0 \mathrm{GHz}$ at $102^{\circ} \mathrm{C}$ for the uniaxially stretched PVDF. The $\varepsilon^{\prime \prime}$ at $102^{\circ} \mathrm{C}$ is seen to decrease rapidly and then level off. At $85^{\circ} \mathrm{C}$, the decrease is very slow, and below $60^{\circ} \mathrm{C}$, no substantial change is observed. Thus, the time dependence of $\varepsilon^{\prime \prime}$ is significant only above the $85^{\circ} \mathrm{C}$, and it becomes stronger as the temperature gets higher. On the other hand, the significant change in $\varepsilon^{\prime}$ was not observed even by annealing at a fixed temperature up to $102^{\circ} \mathrm{C}$.

In sum, the increase in $\varepsilon^{\prime \prime}$ with temperature for uniaxially stretched PVDF suggests that the $\alpha$-relaxation shifts to high frequency. The dielectric loss of uniaxially stretched PVDF decreases when the film is kept standing above $85^{\circ} \mathrm{C}$, and the changes are enhanced with in-

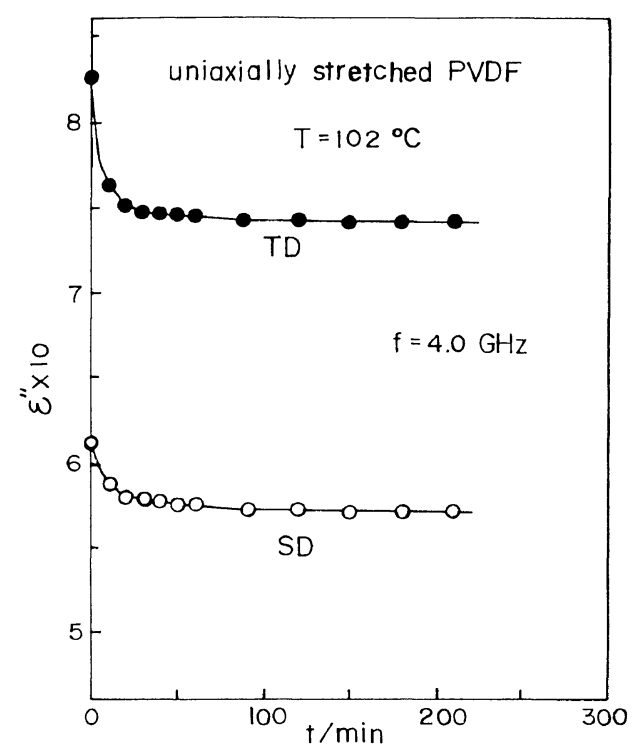

Figure 3. Time dependence of $\varepsilon^{\prime \prime}$ at $4.0 \mathrm{GHz}$ for uniaxially stretched PVDF films at $102^{\circ} \mathrm{C}$ in the TD and SD directions. Unfilled circles, data in the SD; filled circles, data in the TD. 
High Temperature Dielectric Anisotropy at Microwave Frequencies

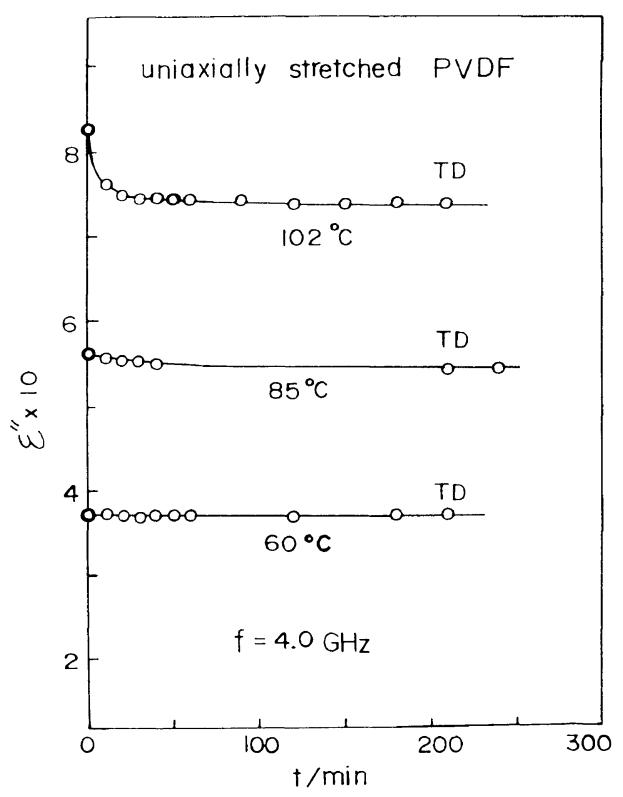

Figure 4. Time dependence of $\varepsilon^{\prime \prime}$ at $4.0 \mathrm{GHz}$ at three different temperatures of $60^{\circ} \mathrm{C}, 85^{\circ} \mathrm{C}$, and $102^{\circ} \mathrm{C}$ in the $\mathrm{TD}$ for uniaxially stretched PVDF.

creasing the standing time and the temperature of dielectric measurement. The finding suggests a possibility that the annealing at high temperatures induces increases in crystallinity ${ }^{23}$ as well as in the relaxation time due to the rearrangement of molecules.

Polymer molecules in the amorphous and interfacial regions tend to crystallize at high temperatures because they can rearrange themselves by micro-Brownian motion liberated at such temperatures. Therefore, the observed decrease in $\varepsilon^{\prime \prime}$ with time may be ascribed to the decrease with time in the number of chain segments responsible for the $\alpha$-relaxation.

The annealing at temperatures up to $102^{\circ} \mathrm{C}$ gave a bit of change in the dielectric anisotropy. This may be ascribed to the liberation of micro-Brownian motion of PVDF molecules at such temperatures.
The apparatus used in this work allows $\varepsilon^{\prime \prime}$ at high temperatures to be measured directly. This advantage is useful for studying the dielectric characteristics of plastic containers and packages when used in a microwave oven. In order to enhance heating efficiency of polymeric materials in the oven, it is required that their high temperature dielectric loss at microwave frequencies should be low.

\section{REFERENCES}

1. N. G. McCrum, R. E. Read, and G. Williams, "Anelastic and Dielectric Effects in Polymeric Solids," John Wiley \& Sons, New York, N.Y., 1976.

2. Y. Ishida, J. Polym. Sci., 7, 1835 (1969).

3. S. Osaki and Y. Ishida, J. Polym. Sci., Polym. Phys. Ed., 12, 1727 (1974).

4. S. Osaki, Y. Ishida, and K. Yamafuji, Polym. J., 12, 171 (1980)

5. T. M. Shaw and J. J. Windle, J. Appl. Phys., 21, 956 (1950).

6. K. K. Jamwal and A. Dhar, Rev. Sci. Instrum., 52, 767 (1981).

7. S. Matsuoka and X. Quan, Macromolecules, 24, 2770 (1991).

8. S. Osaki, Bull. Jpn. Soc. Print. Sci. Technol., 23, 1 (1981).

9. S. Osaki, Tappi, 70, 105 (1987).

10. S. Osaki, Polym. J., 19, 821 (1987).

11. S. Osaki, J. Appl. Phys., 64, 4181 (1988).

12. K. Yamamoto, S. Osaki, S. Yamashita, and M-o. Yamada, Cell. Mol. Biol., 34, 571 (1988).

13. S. Osaki, J. Appl. Polym. Sci., 37, 527 (1989).

14. S. Osaki, Tappi, 72, 171 (1989).

15. S. Osaki and K. Uranishi, Polymer, 31, 33( 1990).

16. S. Osaki, Sen-i Gakkaishi, 46, 26 (1990).

17. S. Osaki, J. Appl. Phys., 67, 6513 (1990).

18. S. Osaki, Nature, 347, 132 (1990).

19. S. Osaki, J. Polym. Sci., C, 28, 147 (1990)

20. S. Osaki, A. Takakusu, M-o. Yamada, and K. Murakami, Cell. Mol. Biol., 39, 673 (1993).

21. S. Osaki, Polym. J., 25, 1311 (1993).

22. S. Osaki, J. Polym. Sci., Polym. Phys. Ed., 33, 685 (1995).

23. S. Osaki, Polymer, 35, 47 (1994).

24. K. Okuda, T. Yoshida, M. Sugita, and M. Asahina, J. Polym. Sci., B, 5, 465 (1967).

25. S. Osaki and Y. Ishida, J. Polym. Sci., Polym. Phys. Ed., 13, 1071 (1975).

26. M. Sucher and J. Fox, "Handbook of Microwave Measurements," Vol. II, Wiley, New York, N.Y., 1963, Chapter IX, p 495. 